\title{
Desenvolvimento de Plataforma Digital para Ensino de Graduação (Caso do Ensino de Atendimento ao Paciente Traumatizado)
}

\author{
Gerson Alves Pereira Júnior ${ }^{1 *}$, Marcelo Alexandre Santos ${ }^{2}$, Filipe Andrade Bernardi², \\ William Dias Ferreira², André Antonelli Senju², Thaís Helena de Paula Jesus ${ }^{3}$, Eduardo Alexandre Gula ${ }^{4}$ \\ ${ }^{1}$ Departamento de Cirurgia e Anatomia da Faculdade de Medicina de Ribeirão Preto da Universidade de São Paulo \\ 2Programa Interunidades em Bioengenharia (EESC/FMRP/IQSC) da Universidade de São Paulo \\ ${ }^{3}$ Graduanda do curso de Informática Biomédica (FMRP e FFCLRP) da Universidade de São Paulo \\ ${ }^{4}$ Faculdade de Economia, Administração e Contabilidade de Ribeirão Preto da Universidade de São Paulo \\ * Autor para correspondência: gersonapj@fmrp.usp.br
}

\section{RESUMO}

O projeto apresentado permitiu o desenvolvimento de uma plataforma digital educacional interativa, de fácil manuseio, intuitiva, de modo a permitir a análise, o monitoramento e o seguimento do desempenho individual e coletivo. Utilizou o blended learning, que transmite a distância pela internet a maior parte dos conteúdos, e também conta com sessões presenciais, podendo ser estruturado com atividades síncronas ou assíncronas. Também utilizou o conceito de Sala de Aula Invertida (Flipped Classroom) como um modelo de aprendizagem que reorganiza o tempo gasto dentro e fora da classe, transferindo o protagonismo, no processo de aprendizado, dos educadores para os alunos, com o desenho didático de atividades programadas: estudo prévio, pré-teste, acesso aos vídeos, pós-teste, acesso aos casos clínicos como exercícios, fórum de dúvidas, chat e webfólio. Este projeto está sendo utilizado gradativamente pelos alunos do quinto ano da Faculdade de Medicina de Ribeirão Preto para o estudo do atendimento aos pacientes traumatizados, com oportunidade de discussão dos casos vivenciados durante os plantões na Unidade de Emergência do Hospital das Clínicas de Ribeirão Preto. O uso da plataforma digital criada tem sido expandido para outras disciplinas de graduação e pós-graduação, além de projetos de pesquisa.

Palavras-chave: Aprendizagem; Medicina de Emergência; Avaliação Educacional; Informática Médica; Redes de Comunicação de Computadores.

\begin{abstract}
The project has been developed an interactive digital educational platform, easy to use, intuitive, to allow the analysis, monitoring and analysis of individual and collective performance. The project used the blended learning that transmits the learning contentes through on the Internet and the sessions can be structured with synchronous or asynchronous activities. It was also used the concept of flipped classroom as a learning model that reorganizes the spent time in and out of class. The main role in the learning process has been transferred of the educators to students. The didactic design of programmed activities: previous study, pretest, access to videos, post-test, access to clinical cases as exercises, forum, chat and webfolio. This project is being gradually used by the undergraduated students of the 5 th year of the Ribeirão Preto School of Medicine for trauma care patients. There are the opportunity to discuss clinical cases experienced during the shifts at the Emergency Unit of the Hospital das Clínicas de Ribeirão Preto. The use of digital platform has been expanded to other undergraduate and postgraduate courses, and research projects.
\end{abstract}

Keywords: Learning; Emergency Medicine; Education Measurement; Medical Informatics; Computer Communication Networks.

\section{Introdução}

O mundo encontra-se na quarta era da educação a distância, após o uso dos correios, da
Ensinar com as novas mídias será uma revolução se mudarmos simultaneamente os paradigmas convencionais do ensino, que mantêm distantes professores e alunos (Moran, 2001).

televisão, da tecnologia computacional, que é a era da interação entre o homem e a máquina, através da comunicação sincronizada, em tempo real ou não, 
por meio da internet. Sob a óptica da educação, a tecnologia agrega valores que criam novas formas didáticas para a transmissão das informações, possibilitando um ensino mais próximo à realidade, mudando o papel do educador frente ao educando. Os professores passam de transmissores a facilitadores da aprendizagem, pois podem disponibilizar, através do uso das novas tecnologias, meios para os indivíduos desenvolverem suas capacidades de descobrimento, de individualização do processo de aprendizagem e de construção dos próprios conhecimentos (BLANCO \& SILVA, 2002; SCHEGHTMAN, 2003).

Os paradigmas da educação estão mudando para incluir mais modelos de aprendizagem on-line, mista ou híbrida e colaborativa. A aprendizagem on-line ampliou o potencial de colaboração, incorporando pontos de conexão que os alunos podem acessar fora da sala de aula para se reunirem e trocarem ideias sobre um assunto ou projeto, como uma modalidade alternativa para superar limites de tempo e espaço (BENETTI \& VASCONCELOS, 2008).

$\mathrm{A}$ adoção de estratégias tecnológicas na $\mathrm{EaD}$ exige um repensar da relação professor-aluno e dos meios de comunicação e interação que poderão aproximar as pessoas, como também afastá-las. Algumas tendências acenam para que a $\mathrm{EaD}$ adote uma abordagem problematizadora, investigativa e reflexiva, contrapondo-se à lógica de estímulo-resposta, situação esta comum no ensino tradicional em que o conteúdo programático é que conduz o usuário. Essas tendências sinalizam para alunos mais autônomos, maduros e sempre prontos a aprender; contudo, os ambientes devem prover as tecnologias e as facilidades para a implementação da interação, que visa a viabilizar o processo de ensino-aprendizagem (LÉVY, 1999; BELLONI, 2003).

Esse deverá ser o grande diferencial das disciplinas oferecidas na modalidade semipresencial, ou seja, fomentar a aprendizagem colaborativa e estimular o conhecimento compartilhado, mostrando a eficácia dessa estratégia de se fazer $\mathrm{EaD}$ (LITWIN, 2001; TAVARES, 2006).
A aprendizagem colaborativa é um processo importante para o compartilhamento de um objetivo comum, e sua metodologia envolve a interação, que deve romper a lógica de ensino tradicional para uma prática mais inovadora, promovendo uma relação afetiva com o conhecimento, de forma reflexiva e mais autônoma (TORRES \& IRALA, 2014).

Pensar a prática pedagógica para a educação on-line é antes de qualquer coisa pensar um desenho didático interativo cuja arquitetura deve envolver o planejamento, a produção e a operatividade de conteúdos e de situações de aprendizagem, que estruturam processos de construção do conhecimento na sala de aula on-line. Esses conteúdos e situações de aprendizagem devem contemplar o potencial pedagógico, comunicacional e tecnológico do computador, bem como das disposições de interatividade próprias dos ambientes de aprendizagem on-line (KENSKI, OLIVEIRA \& CLEMENTINO, 2006; SILVA \& SANTOS, 2009).

As plataformas on-line podem ser usadas para facilitar grupos de resolução de problemas e construir habilidades de comunicação, enquanto avançam no conhecimento do assunto estudado. $\mathrm{O}$ e-learning é "o processo pelo qual o aluno aprende através de conteúdos colocados no computador e/ou internet e em que o professor, se existir, está a distância, utilizando a internet como meio de comunicação de forma síncrona ou assíncrona, podendo existir sessões presenciais intermédias" (KENSKI, OLIVEIRA \& GLEMENTINO, 2006; GLARK \& MAYER, 2007; MORAN, 2001).

$\mathrm{O}$ blended learning é um derivado do e-learning, que transmite a distância pela internet a maior parte dos conteúdos, e também conta com sessões presenciais, podendo ser estruturado com atividades de comunicação em tempo real, como chats e web-conferências (síncronas) e de comunicação em diferentes tempos, como correio eletrônico, fóruns, listas de discussão, portfólios, diários, blogs, glossários, wikis (assíncronas) (SILVA \& SANTOS, 2009; MATTE, 2009).

A Sala de Aula Invertida (Flipped Classroom) tranformou-se em referência a um modelo de aprendizagem que reorganiza o tempo gasto dentro e fora da classe, 
transferindo o protagonismo no processo de aprendizado, dos educadores para os alunos. Assim, o valioso tempo presencial de aula é dedicado a uma aprendizagem mais ativa, com projetos baseados no aprendizado e nos quais os alunos trabalham em conjunto ou isoladamente para resolverem os desafios locais e globais (ou outras aplicações do mundo real), obtendo uma compreensão mais profunda do assunto. $\mathrm{O}$ ambiente de aprendizagem se transforma em um espaço dinâmico e mais social, onde os alunos podem participar de críticas ou trabalhar através de problemas atuando em equipes (ELLAWAY \& MASTERS, 2008; NEEL, LAU, DOHERTY \& HARBUTT, 2015; MOFFETT, 2015).

O estudo com a utilização de casos clínicos em Medicina abrange situações baseadas em fatos reais ou uma construção de eventos com objetivos específicos para análise, interpretação, aplicação de informações e conceitos aprendidos nas aulas e na literatura médica (GOLICH, 2000; ONLINE LEARNING CENTRE). Os professores podem envolver seus alunos mais plenamente na discussão em sala de aula por meio do estudo dos casos, os quais se tornam passíveis de ser utilizados como estudo prévio antes da aula, discussão durante a aula presencial para fixação de conceitos e/ou após aula como exercícios (DOWNER \& SWINDELLS, 2003; KOLODNER, HMELO \& NARAYANAN, 1996). Neste modelo, o método associa a aprendizagem ativa autodirigida dos alunos ao estudo independente guiado pela experiência do professor, que sabe escolher a sequência de casos que motivarão e envolverão os alunos em seus estudos. Em adição, pode ser utilizado na educação a distância dentro de uma plataforma digital para complementar o estudo e sedimentar os conceitos e a sequência de raciocínio diagnóstico e terapêutico (BALBACH, 1999).

$\mathrm{O}$ raciocínio baseado em casos corresponde ao modelo de pensamento natural do ser humano. Esta abordagem é semelhante àquela utilizada pelos médicos quando cogitam: "Vi um paciente assim", propiciando lembrança imediata de casos passados, que levantam informações relevantes para o presente caso, contribuindo para a resolução de problemas similares quanto às informações da anamnese e do exame físico, hipóteses diagnósticas, uso racional de exames complementares e das diferentes abordagens terapêuticas. Os conceitos didáticos e métodos utilizados seguem os princípios das teorias de aprendizagem de adultos, que enfatizam a importância da aplicabilidade prática do conhecimento, sendo o raciocínio baseado em casos um paralelo ao processo de resolução de problemas, e que contribuem fortemente para a motivação dos estudantes.

A incorporação da simulação como ferramenta fundamental nos diversos níveis de formação é atualmente uma necessidade. A aprendizagem de competências com o uso da simulação garante um ambiente de maior segurança para os pacientes na prática clínica e uma aprendizagem maior e mais permanente no tempo (McGAGHIE, ISSENBERG, PETRUSA et al., 2010; AKAIKE, FUKUTOMI, NAGAMUNE et al., 2012; MOTOLA, DEVINE, CHUNG et al., 2013).

A estruturação dos casos simulados possibilita o desenvolvimento de ideias que permitem o envolvimento significativo dos alunos nas discussões de condutas a serem tomadas com base na presença ou não de recursos humanos, diagnósticos e terapêuticos existentes nos diferentes níveis de atenção à saúde. Este método também associa a aprendizagem autodirigida dos alunos à experiência do professor no momento de escolha da sequência de casos simulados, que podem incluir o uso de habilidades psicomotoras, habilidades de comunicação e situações de tomada de decisões, em que pode ser planejado o uso de fatores de confusão (distratores) que mais frequentemente ocorrem na experiência prática e que irão auxiliar na motivação e envolvimento dos alunos em seus estudos (McGULLOCH, RATHBONE \& CATCHPOLE, 2011; BURFORD, 2012).

A simulação permite que os alunos treinem à vontade suas competências (conhecimentos, habilidades e atitudes), não se importando com eventuais erros, que devem ser corrigidos, diferentemente da assistência direta em pacientes reais, possibilitando a redução da pressão e do grau de estresse no momento de realização da prática assistencial, e aumenta a segurança do paciente. $\mathrm{O}$ preparo dos 
alunos para as atividades práticas simuladas também pode ser realizado dentro de uma plataforma digital, com apresentações, vídeos e discussões antecipando as situações, problemas e dúvidas mais frequentes que o professor conhece dentro de sua experiência prévia com aquela atividade. Isto permite em cada caso simulado a ampla exploração das diferentes dimensões das competências dos alunos, sejam cognitivas, afetivas, psicomotoras ou das diversas combinações delas, atuando como uma equipe de atendimento (LERNER, MAGRANE \& FIEDMAN, 2009; BAKER et al., 2010; WELLER et al., 2011).

No contexto da pedagogia da transmissão, o desenho didático produzido não se transforma ao longo da docência, limitando-a à execução de conteúdos e de situações de aprendizagem fechados como pacotes de informação. Essa postura revela a separação entre aqueles que pensam e produzem o desenho didático e aqueles que executam as atividades práticas assistenciais, tendo os alunos a sensação de que "na prática, a teoria é diferente". "O desenho didático deve ser aberto para utilizar as informações que aparecem na ação, integrando-as, formulando esquemas de ação e deve-se estar apto para reunir o máximo de certezas para enfrentar a incerteza." (MORIN, 2000). O desenho didático assim entendido requer competências específicas de atuação dos docentes e dos alunos, fazendo da plataforma digital um campo de possibilidades para a construção do conhecimento na sala de aula on-line. Este é um momento oportuno para a inclusão da educação interprofissional e de atuação interdisciplinar, articulando diversos saberes (SILVA \& SANTOS, 2009; SILVA, 2003, pp. 5375).

Outra mudança que está ocorrendo na prática pedagógica em todo o mundo é que os estudantes estão aprendendo, fazendo e criando, ao invés de apenas consumirem os conteúdos. A criatividade está cada vez mais presente na forma de aprendizagem prática (NMC Horizon Report).

O professor precisará estar convencido de que, em lugar de substituí-lo, as interfaces on-line vêm potencializar sua autoria (SILVA \& SANTOS,
2009; SILVA, 2003). Na sala de aula on-line, o desenho didático interativo conta com o professor formulador de interrogações, coordenador de equipes de trabalhos e sistematizador de experiências. No lugar do guardião do conhecimento e disparador de lições-padrão de pedagogia da transmissão, o professor precisará acionar a participação do aluno, sabendo que a comunicação e o conhecimento se constroem como cocriação, como expressão e confrontação das subjetividades, sabendo que a fala livre e plural supõe lidar com as diferenças na construção da tolerância e da democracia (SILVA \& SANTOS, 2009; SILVA, 2003).

Há um crescente interesse no uso de novas fontes de dados para personalizar a experiência de aprendizagem e de medição de desempenho. Ao participarem de atividades on-line, os alunos deixam dados que podem ser extraídos para uma maior compreensão. Experiências e projetos de demonstração em análise da aprendizagem (Learning Analytics) estão atualmente analisando formas de utilizar esses dados para modificar estratégias e processos de aprendizado. Espera-se que essas informações permitam uma maior personalização da aprendizagem com melhoria contínua dos resultados, o que favorece um engajamento mais profundo dos alunos para a aprendizagem em ambientes virtuais. A tecnologia pode ajudar a detectar padrões de sucessos e fracassos dos alunos com o material do curso e oferece aulas personalizadas de acordo com cada aluno (NMC Horizon Report).

Mesmo com toda essa evolução, a formação do corpo docente ainda não reconhece o fato de que o letramento em mídias digitais continua a sua ascensão em importância como uma habilidade fundamental em cada disciplina e profissão (NMG Horizon Report). Para que todas estas possibilidades de estratégias e tecnologias educacionais potencializadas pelos novos tempos na educação sejam colocadas em prática, é preciso que professores e alunos tenham acesso a uma plataforma educacional interativa, de fácil manuseio, intuitiva, de modo a permitir a análise, o monitoramento e o seguimento do desempenho individual e coletivo. 
A educação a distância foi reconhecida pelo Ministério da Educação e Cultura (MEG) na década de 1990, a partir da Lei n. 9394/96. As disciplinas semipresenciais foram expressas pela portaria 4.059/04 do MEG, que em seu Artigo $1^{\circ}$ dispõe que "as instituições de Ensino Superior poderão introduzir, na organização pedagógica e curricular de seus cursos superiores reconhecidos, a oferta de disciplinas integrantes do currículo que utilizem modalidade semipresencial, podendo utilizar 20\% da carga horária total do curso para atividades de EaD" (BRASIL, 2004). Admite-se como modalidade semipresencial a aplicação de didáticas que permitam a autoaprendizagem do educando a partir de tecnologias de comunicação remotas. Assim, as plataformas digitais podem ser utilizadas como suporte "às atividades de formação semipresencial, nas quais o ambiente digital poderá ser utilizado tanto nas ações presenciais como nas atividades a distância" (ALMEIDA, 2003).

\section{Desenvolvimento da Plataforma Digital}

O objetivo do projeto aprovado no Programa Pró-Ensino 2013, intitulado "Projeto de Apoio
Didático ao Estudo do Atendimento ao Trauma por Ensino a Distância (EaD)", foi o desenvolvimento de uma plataforma educacional interativa, de fácil manuseio, intuitiva, de modo a possibilitar a análise, o monitoramento e o seguimento do desempenho individual e coletivo. Foi utilizado o b-learning com atividades síncronas e assíncronas como apoio didático aos alunos do quinto ano da Faculdade de Medicina de Ribeirão Preto para o estudo do atendimento aos pacientes traumatizados, com oportunidade de discussão dos casos vivenciados durante os plantões na Unidade de Emergência do Hospital das Clínicas de Ribeirão Preto.

Este projeto interdisciplinar entre a área da saúde (medicina e enfermagem) e a informática biomédica continua em desenvolvimento permanente para sua utilização em diversas disciplinas de graduação e outras finalidades, como em disciplinas e projetos de pós-graduação. Tal cooperação entre profissionais de diferentes formações tem como base outras plataformas digitais existentes, aperfeiçoando as ferramentas que permitam cumprir todas as tarefas didaticamente desenhadas para cada sessão de aprendizagem. Os alunos acessam o software de $\mathrm{EaD}$ sediado na

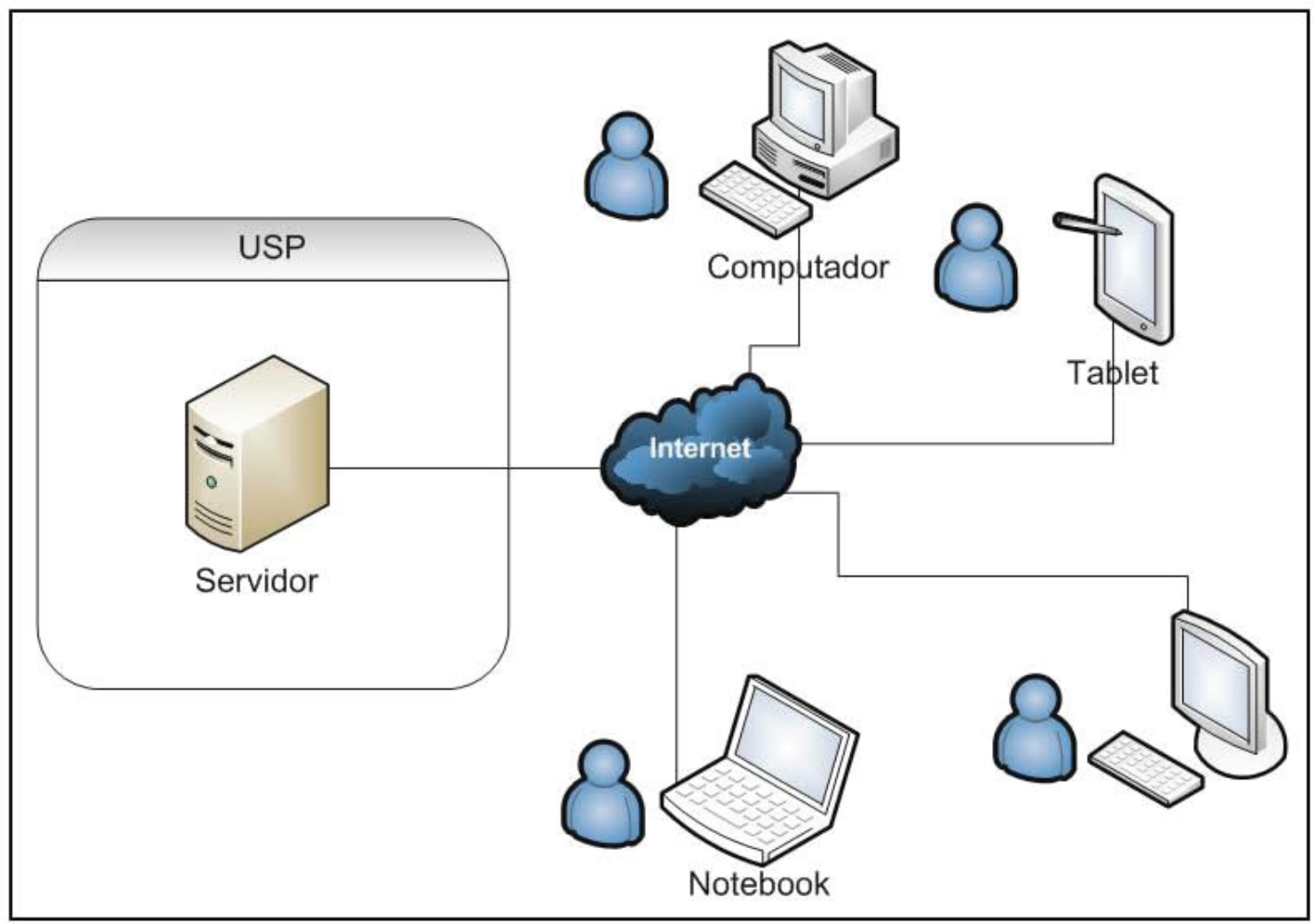

Figura 1 - Acesso dos alunos ao servidor. 
Nuvem USP após cadastro através de diferentes dispositivos, via web (Figura 1).

O projeto compreende a abordagem de tópicos do atendimento ao traumatizado, sendo já filmados os seguintes vídeos: Organização da Rede de Atendimento às Urgências e Emergências, Atendimento Inicial, Vias Aéreas e Ventilação, Choque Circulatório, Trauma Torácico, Trauma Abdominal e Pélvico, Trauma Cranioencefálico, Trauma Vertebromedular, Trauma Músculo-Esquelético, Atendimento Inicial ao Paciente Queimado e Trauma em Pacientes Especiais (Criança, Mulher e Idoso). Cada um desses tópicos é desenvolvido em sessões com o seguinte formato:

Calendário de atividades;

Textos selecionados para estudo prévio;

Pré-teste de verificação dos conhecimentos;

Aula gravada em vídeo e editada;

Pós-teste de verificação dos conhecimentos;

Envio de situações/casos clínicos para estudo e/ou discussão em grupo;

Chats com horário marcado para discussão do estudo em grupos e tira-dúvidas com o professor;

Preenchimento do portfólio ao final de cada sessão, contendo reflexões sobre o estudo do tópico e a avaliação de pontos positivos e negativos.
Tal software propicia diferentes funcionalidades para os alunos e para os professores, como pode ser visto nas Figuras 2 e 3:

Os alunos do quinto ano são divididos em subturmas, com esquema de rodízio a cada seis semanas, durante todo o ano letivo. A dinâmica desse curso de apoio ao estudo de trauma através do EaD é a seguinte (Figura 4):

- Cada aluno matriculado recebe um nome de usuário e senha para acesso ao programa.

- Cada sessão tem a duração de dias, sendo possível muita flexibilidade de tempo e na organização dos estudos pelos próprios alunos.

- Após os estudos orientados pelos roteiros de cada tema com a leitura dos textos sugeridos para a sessão, o aluno faz o login para a realização do pré-teste (com dez testes de múltipla escolha on-line e com correção automática), tendo quinze minutos para concluir. Será aprovado se obtiver nota igual ou superior a 70\% do total e deve assistir ao vídeo imediatamente. Se o aluno não atingir esse desempenho, terá mais quatro horas de estudo para repeti-lo até ser aprovado. Há um banco de questões que randomiza a escolha dos testes e suas alter-

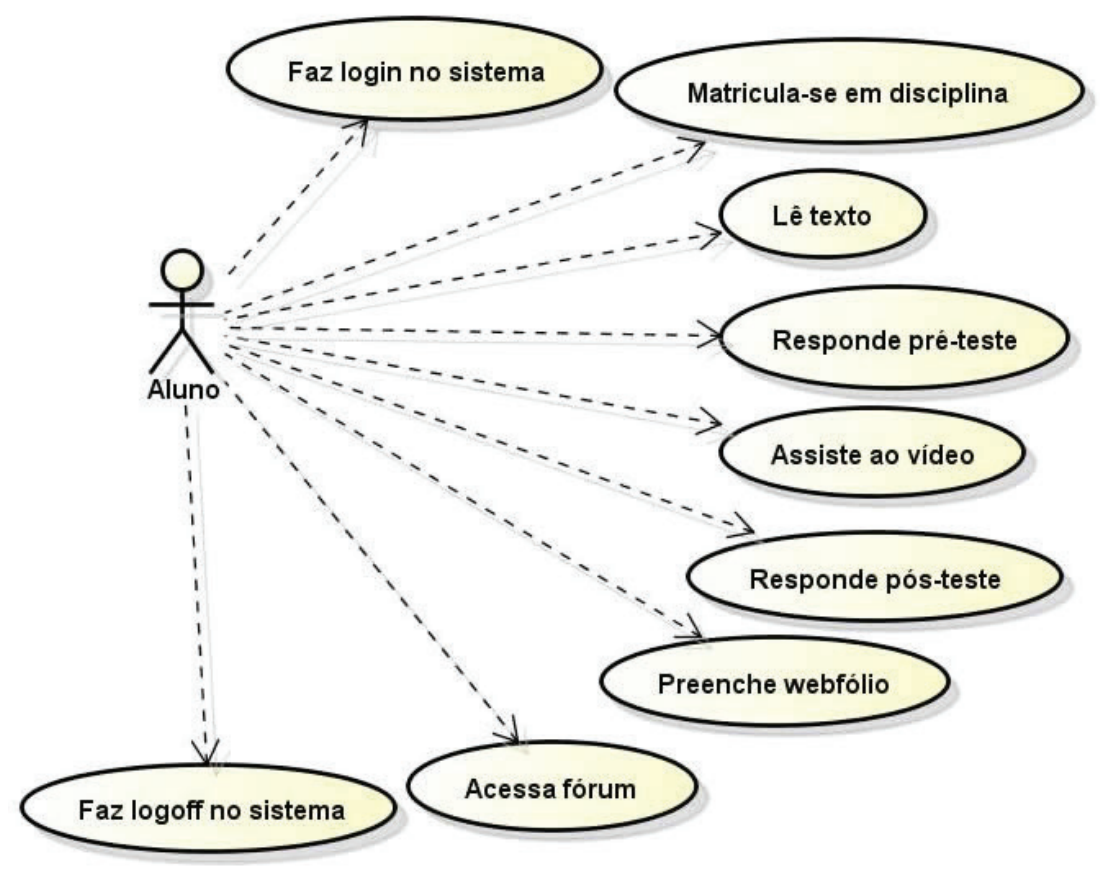

Figura 2 - Demanda para os alunos. 


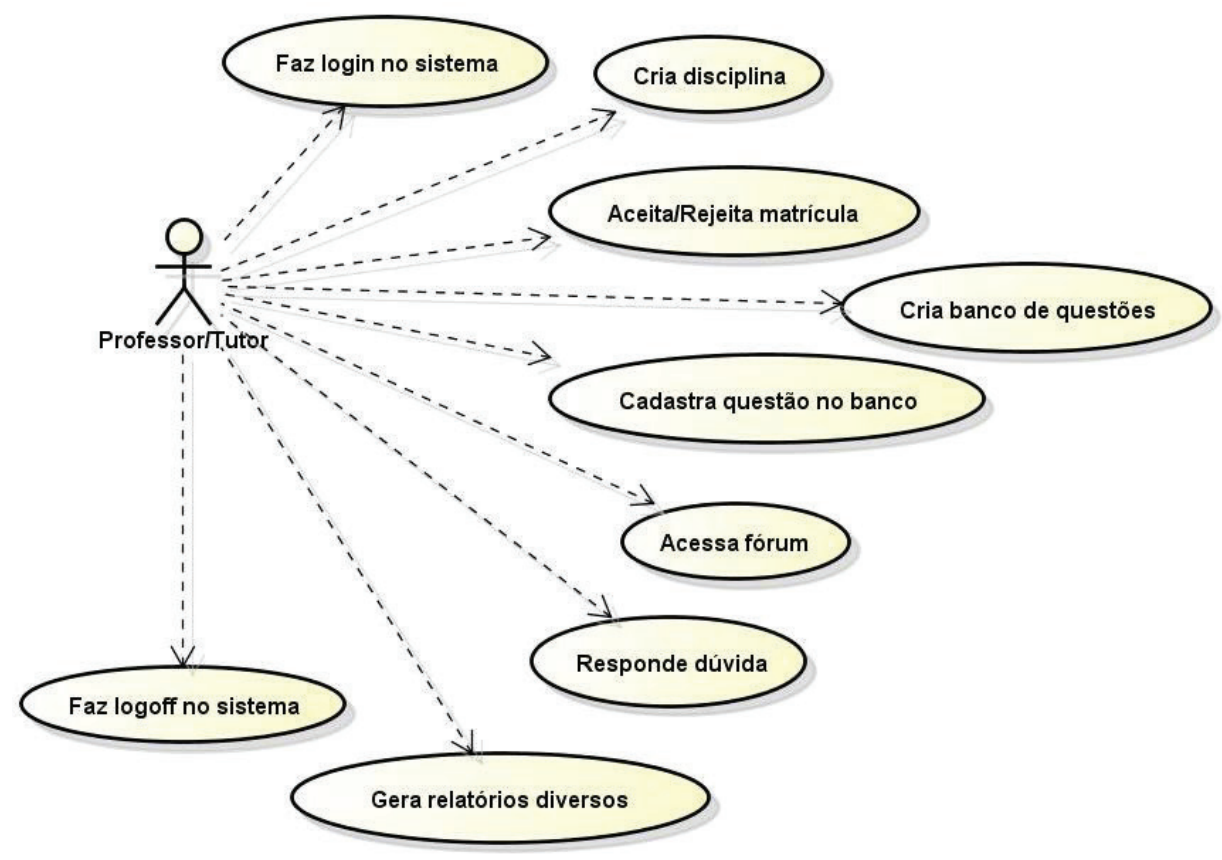

Figura 3 - Demanda para os professores.

nativas, permitindo a correção automática com definição do percentual de acerto.

- Os vídeos com duração média de trinta minutos mostram o professor apresentando os tópicos com edições mostrando detalhes de procedimentos em laboratório de simulação e cenas reais.

- Depois de assistir ao vídeo, o aluno terá até seis horas para fazer o pós-teste (também dez testes de múltipla escolha com correção automática), tendo quinze minutos para concluir o teste. Será aprovado se obtiver nota igual ou superior a $80 \%$ do total. Se o aluno não atingir este aproveitamento, terá mais quatro horas para assistir novamente ao vídeo e repetir o pós-teste até ser aprovado. Caso o aluno exceda as seis horas para realização do pós-teste, terá que retornar novamente ao início dessa mesma sessão, fazendo o pré-teste.

- Terminado o pós-teste, os alunos receberão dois casos clínicos para estudo e discussão, de preferência em conjunto com os demais colegas.

- Em cada sessão, os alunos poderão enviar questões para um fórum. Estas serão respondidas pelo professor, podendo ser público (todos os alunos veem as questões) ou privado (restrito ao aluno com dúvida e ao professor). Esta decisão pode ser deixada para o professor e/ou os alunos.

- Há agendamento de um chat - encontro com hora marcada, quando todos devem estar logados através do software para discussão com o professor.

- Após o chat, os alunos devem preencher o webfólio com a reflexão sobre os conhecimentos adquiridos e os pontos positivos/negativos da sessão.

- Depois de completar o webfólio, os alunos passam à próxima sessão, reiniciando este mesmo ciclo.

Ao término do conjunto de cada três sessões on-line, é programado um encontro presencial englobando todos os alunos e o professor, para discussão de situações práticas de atendimento, retirada de dúvidas e discussão de novos casos clínicos.

Como disposto na operacionalização das sessões do projeto, a plataforma digital deve conter e armazenar conteúdos de aprendizagem, propostas de trabalho e de avaliações e, no mesmo ambiente, dispor de interfaces de construção da comunicação e do conhecimento. $\mathrm{O}$ desenho didático é a estrutura de apresentação do conjunto de conteúdos e de situações de aprendizagem, compostos e dispostos estrategicamente de modo 


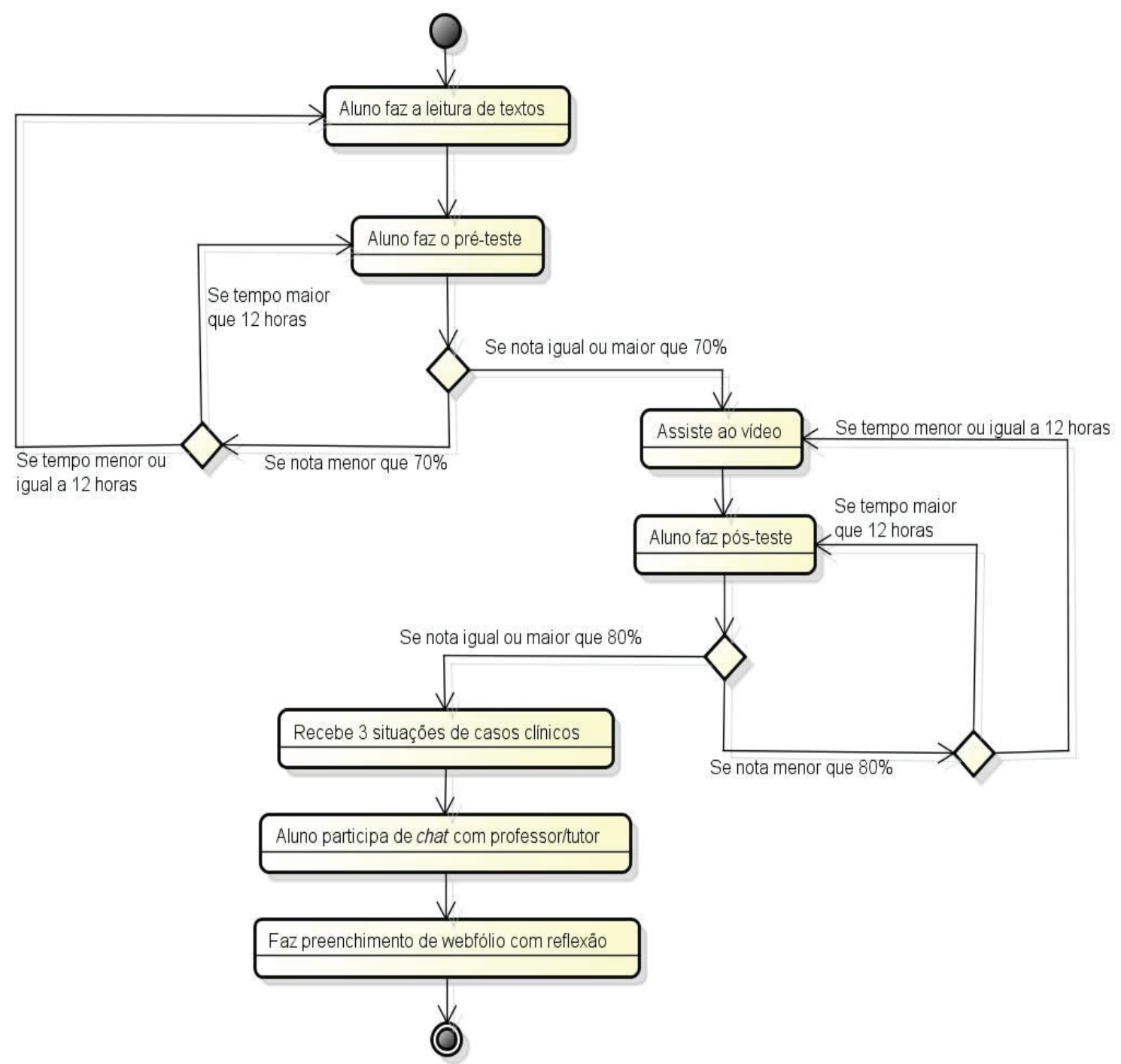

Figura 4 - Fluxo das atividades em cada sessão de EaD.

a serem utilizados pelo professor e pelos alunos com a finalidade de potencializar a construção coletiva da comunicação, do conhecimento, da docência, da aprendizagem e da avaliação.

Em relação ao aspecto técnico do desenvolvimento, para a programação do software foi usada a linguagem PHP associada ao framework CodeIgniter, e as telas foram construídas com uso de Bootstrap. $\mathrm{O}$ armazenamento de dados se dá com o banco de dados MySQL. A interface do software foi criada com o conceito de responsividade, que é quando as telas do software se adaptam automaticamente às diferentes dimensões de telas dos dispositivos como notebooks, tablets e smartphones.

A Figura 5 mostra a tela atual dos módulos vista pelos alunos do quinto ano ao acessarem a Nuvem
USP e logarem na disciplina. Ao clicar em cada módulo, os alunos fazem as atividades propostas.

$\mathrm{O}$ software permite o acesso às seguintes informações:

- Data/hora de cada acesso ao software pelo aluno e seu tempo de acesso, passando a ter seu registro de frequência;

- Para cada acesso, quais atividades foram acessadas pelo aluno (textos, vídeo etc.);

- Dentre as atividades acessadas, qual a data/ hora de acesso e o tempo registrado para cada uma;

- Controle do tempo total de conexão, tempo médio e mediano em cada atividade dentro das sessões, quantidade de acessos de cada atividade (leitura de cada texto, resolução do 


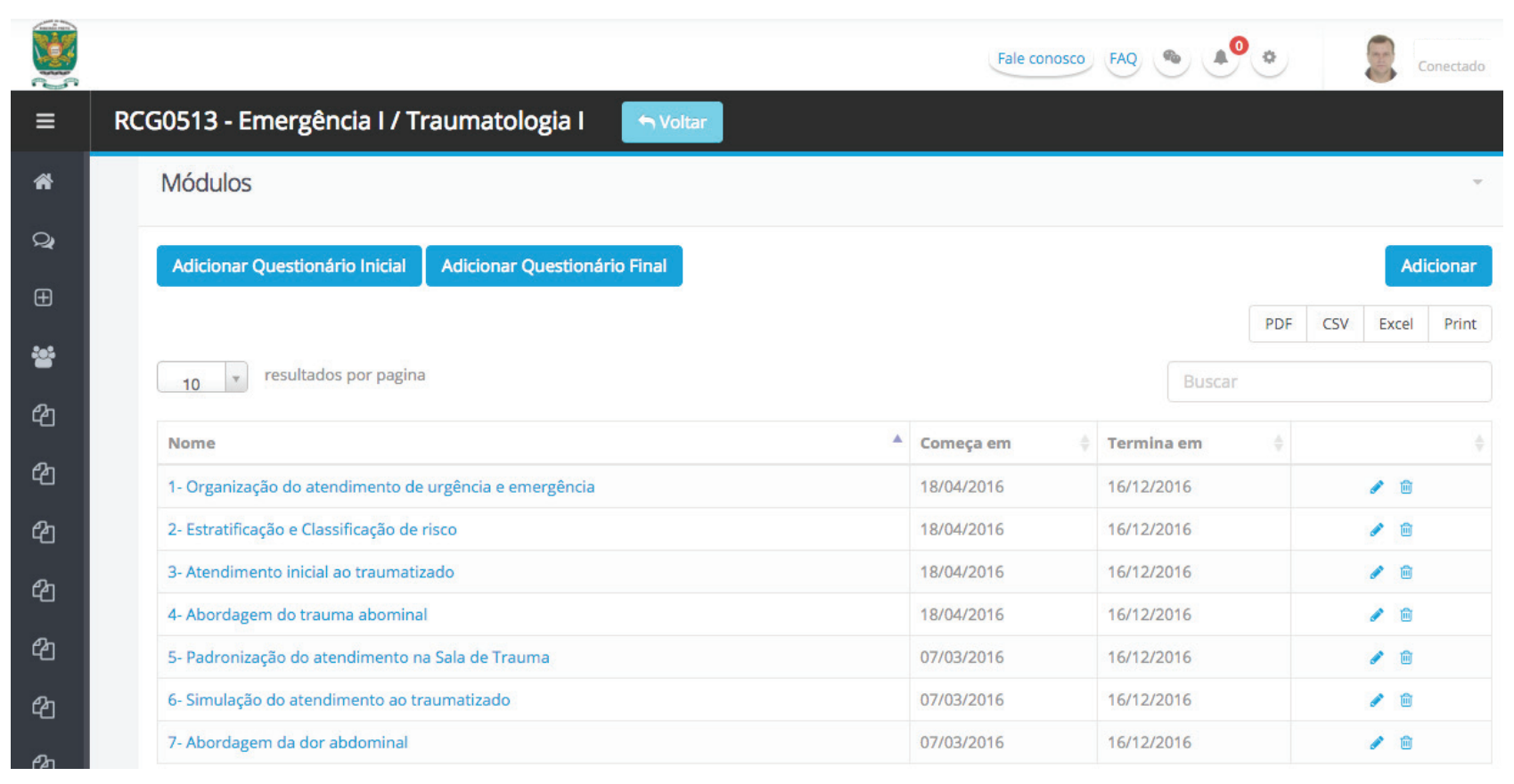

Figura 5 - Exemplo da tela do software.

pré e pós-teste e visualização da videoaula); registro do maior e do menor tempo de conclusão da sessão;

- Controle do tempo de acesso entre as sessões;

- Quantidade de acertos/erros máxima, mínima, média e mediana do pré e pós-teste de cada sessão;

- Definição das questões utilizadas ou não em cada módulo especificamente;

- Correção automática das avaliações pré e pós-teste com exibição do percentual de acerto;

- Mostrar o webfólio preenchido pelo aluno para avaliação e feedback;

- Evolução individual por aluno ao longo da disciplina, considerando suas notas de pré e pós-teste;

- Evolução comparada individual do aluno em relação aos demais ao longo da disciplina, com base em suas notas de pré e pós-teste.

\section{Conclusão}

A flexibilidade e a facilidade operacional da plataforma digital que se encontra em constante desenvolvimento com inclusão de novas ferramentas e funções têm tornado sua utilização cada vez mais frequente em disciplinas regulares e optativas da graduação. Os diferentes tipos de materiais de ensino têm sido postados e disponibilizados gra- dativamente para os alunos. Isso faz com que eles possam se preparar melhor, com autonomia de acesso aos diversos materiais e controle do tempo de estudo, valorizando o precioso tempo presencial para esclarecimento de dúvidas do estudo prévio, discussão de casos clínicos vivenciados na prática assistencial e foco nas atividades práticas simuladas.

O projeto procura trabalhar aprimorando todas as tendências apontadas na literatura e antecipa as implicações educacionais discutidas. Desse modo, prevê o desenvolvimento de um ambiente virtual de aprendizagem com facilitação da interface para professores e alunos; aprendizado on-line, híbrido e colaborativo; lidando com diversas ferramentas de informática de modo interativo, uso de diferentes formas de avaliação no formato digital com resultados integrados a um sistema de análise do desempenho individual e coletivo dos alunos.

O uso da plataforma digital criada tem sido expandido para outras disciplinas de graduação e pós-graduação, além de projetos de pesquisa, de modo a permitir uma excelente oportunidade de educação interprofissional.

\section{Agradecimentos}

Agradecemos à Pró-Reitoria de Graduação da USP, ao Programa de Pós-Graduação Interunidades em Bioengenharia (EESC/FMRP/ 
IQSSC-USP), à Coordenação de Aperfeiçoamento de Pessoal de Nível Superior (Capes) e ao Conselho Nacional de Desenvolvimento Científico e Tecnológico ( $\mathrm{CNPq}$ ) o apoio aos projetos e bolsas de iniciação científica e pós-graduação.

\section{Referências Bibliográficas}

AKAIKE, M.; FUKUTOMI, M.; NAGAMUNE, M. et al. "Simulation-Based Medical Education in Clinical Skills Laboratory". F. Med. Invest., vol. 59, 2012, pp. 28-35.

ALMEIDA, Maria Elizabeth Bianconcini. Avaliação em Meio Digital: Novos Espaços e Outros Tempos. São Paulo: PUC/SP-CED, 2003.

BAKER, D. P.; AMODEO, A. M.; KROKOS, K.J.; SLONIM, A.; HERRERA, H. "Assessing Teamwork Attitudes in Healthcare: Development of the TeamSTEPPS Teamwork Attitudes Questionnaire". Qual Saf Health Care pp. 1-4, 2010.

BALBACH, E. D. Using Case Studies to Do Program Evaluation. Sacramento, CA: California Department of Health Services, 1999. Disponível em: http://www. case.edu/affil/healthpromotion/ProgramEvaluation.pdf. Acessado em 24 mar. 2016.

BELLONI, Maria Luiza. Educasãao a distância. 3. ed. Campinas: Autores Associados, 2003.

BENETTI, G. R. \& VASCONCELOS, M. F. "Ensino a Distância: Sujeitos na Rede: Novas Tecnologias de Informação e Comunicação", 2008. Disponível em: http://www.abed.org.br/congresso2008/ tc/520200812712PM.pdf. Acessado em 12 mar. 2013.

BLANCO, E \& SILVA, B. Tecnologia e Educasão. Portugal: Porto, 2002.

BRASIL, Ministério da Educação e Cultura (MEC). "Portaria 4.059/04", 2004. Disponível em http://portal. mec.gov.br/sesu/arquivos/pdf/nova/acs_portaria4059. pdf. Acessado em 13 mar. 2013.

BURFORD, B. "Group Processes in Medical Education: Learning from Social Identity Theory". Med. Educ., vol. 46, n. 2, 2012, pp. 143-52.

CLARK, R. C. \& MAYER, R. E. E-Learning and the Science of Instruction: Proven Guidelines for Consumers: and Designers of Multimedia Learning. New York: Pfeiffer, 2007.

DOWNER, Ann \& SWINDELLS, Sue. "Developing Clinical Case Studies: A Guide for Teaching", 2003. Disponível em: http://www.go2itech.org/HTML/ CM08/toolkit/tools/print/casebased/De veloping_Clinical_Case_Studies.pdf. Acessado em 24 mar. 2016.

ELLAWAY, R. \& MASTERS, K. "AMEE Guide 32: E-Learning in Medical Education. Part 1: Learning, Teaching and Assessment". Medical Teacher, vol. 30, n. 5, pp. 455-473, 2008.
GOLICH, V. L. "The ABCs of Case Teaching". International Studies Perspectives, vol. 1, pp. 11-29, 2000.

KENSKI, V. M.; OLIVEIRA, G. P. \& CLEMENTINO, A. "Avaliação em Movimento: Estratégias Formativas em Curso On-Line". In: SILVA, Marco \& SANTOS, Edméa (orgs.). Avaliação da Aprendizagem em Educaşão On-Line. São Paulo: Loyola, 2006, pp. 79-108.

KOLODNER, Janet L.; HMELO, Cindy E. \& NARAYANAN, N. Hari. Problem-Based Learning Meets Case-Based Reasoning". In: EDELSON, Daniel C. \& DOMESHEK, Eric A. (eds.). Proceedings of the 1996 International Conference on Learning Sciences (ICLS '96), International Society of the Learning Sciences, 1996, pp. 188-195.

LERNER, S.; MAGRANE, D. \& FIEDMAN, E. "Teaching Teamwork in Medical Education". Mount Sinai Fournal of Medicine, vol. 76, 2009, pp. 318-329.

LÉVY, Pierre. As Tecnologias da Inteligência: o Futuro do Pensamento na Era da Informática. Lisboa: Instituto Piaget, 1999.

LITWIN, Edith. Educasão a Distância. Temas para o Debate de uma Nova Agenda Educativa. Porto Alegre: Artmed, 2001, pp. 13-22.

MATTE, Ana Cristina Fricke. "Análise Semiótica da Sala de Aula no Tempo da EAD". Revista Tecnologias na Educação, vol. 1, 2009, p. pal3.

McCULLOCH, P.; RATHBONE, J. \& CATCHPOLE, K. "Interventions to Improve Team-Work and Communications among Health Care Staff". Br. F. Surg., vol. 98, n. 4, 2011, pp. 469-79.

McGAGHIE, W. C.; ISSENBERG, S. B.; PETRUSA, E. R.; SCALESE, R. J. "A Critical Review of Simulation-based Medical Education Research: 20032009". Med. Educ., vol. 44, 2010, pp. 50-63.

MOFFETT, J. "Twelve Tips for 'Flipping' the Classroom". Medical Teacher, vol. 37, pp. 331-336, 2015.

MORAN, J. M. "Novos Desafios na Educação: a Internet na Educação Presencial e Virtual". In: PORTO, Tânia Maria E.(org.). Saberes e Linguagens de Educação e Comunicaşão. Pelotas: Editora da UFPel, 2001, pp. 1944.

MORIN, Edgar. Os Sete Saberes Necessários à Educação do Futuro. Brasília, DF: Ed. Cortez/Unesco, 2000.

MOTOLA, I.; DEVINE, L. A.; CHUNG, H. S. et al. "Simulation in Health Care Education: a Best Evidence Practical Guide. AMEE Guide n. 82". Medical Teacher, vol. 35, n. 10, 2013, pp. 1511-1530.

NEEL, S.; LAU, C. S.; DOHERTY, I. \& HARBUTT, D. "How We Flipped the Medical Classroom". Medical Teacher, vol. 37, pp. 327-330, 2015.

NMC Horizon Report: 2014 Higher Education Edition. Disponível em: http://www.nmc.org/pdf/2014nmchorizonreportheEN.pdf. Acessado em 22 mar. 2016.

ONLINE Learning Centre. "Writing Case Studies: a Manual". Disponível em: http://www.ntu.edu.vn/ 
Portals/96/Tu $\% 20$ lieu $\% 20$ tham $\% 20$ khao/Phuong $\% 20$ phap $\% 20$ giang $\% 20$ day/case $\% 20$ writing $\% 20$ manual. pdf. Acessado em 24 mar. 2016.

SCHECHTMAN, S. "Interatividade entre Orientador e Aprendiz em um Curso Virtual: Prática ou Teoria?", 2003. Disponível em: http://www.rautu.unicamp.br/nou$\mathrm{rau} /$ ead/document/?code=18. Acessado em 28 mar. 2013.

SILVA, M. "Criar e Professorar um Curso On-Line”. In: SILVA, M. (org.). Educaşão Online. São Paulo: Loyola, 2003, pp. 5375.

"Sala de Aula Interativa: a Educação Presencial e a Distância em Sintonia com a Era Digital e com a Cidadania". 2003. Disponível em http://www.senac.br/informativo/BTS/272/boltec272e.htm. Acessado em 22 mar. 2016.

\& SANTOS, E. "O Desenho Didático Interativo na Educação On-Line". Revista Ibero-Americana,
Espanha, n. 49, jan./abr. 2009. Disponível em: http:// www.rieoei.org/rie49a11.htm. Acessado em 6 jan. 2013.

TAVARES, Valéria Ribeiro de Carvalho. "O Ambiente Inovador da EAD como Agente de Mudanças e Transformações das Práticas Pedagógicas". Revista Eletrônica SEED MEC, Brasília, 2006.

TORRES, P. L. \& IRALA, E. A. F. "Aprendizagem Colaborativa: Teoria e Prática", 2014. Disponível em: http://www.agrinho.com.br/site/wp-content/ uploads/2014/09/2_03_Aprendizagem-colaborativa.pdf. Acessado em 20 mar. 2016.

WELLER, J.; FRENGLEY, R. W.; TORRIE, J.; SHULRUF, B.; JOLLY, B.; HOPLEY, L.; HENDERSON, K.; DZENDROWSKYJ, P.; YEE, B.; PAUL, A.. "Evaluation of an Instrument to Measure Teamwork in Multidisciplinary Critical Care Teams". BMF Qual Saf, vol. 20, 2011, pp. 216-222.

Publicado em 31/03/2017. 